\title{
Protein C Inhibitor Is Expressed in Tubular Cells of Human Kidney
}

\author{
Klaus-P. Radtke, ${ }^{\star \|}$ José A. Fernández, ${ }^{\star \star}$ Judith S. Greengard, ${ }^{\star \star}$ Winson W. Tang, ${ }^{5}$ Curtis B. Wilson, ${ }^{5}$ David J. Loskutoff, ${ }^{\star}$ \\ Inge Scharrer," and John H. Griffin * \\ *Departments of Molecular and Experimental Medicine, ${ }^{\ddagger}$ Vascular Biology, and ${ }^{\S}$ Immunology, The Scripps Research Institute, La Jolla, \\ California 92037; and "Klinikum der Johann Wolfgang Goethe Universität, Frankfurt, Germany
}

\begin{abstract}
Protein $\mathrm{C}$ inhibitor (PCI) is a serpin that inhibits a number of proteases. PCI is found in urine and binds to kidney epithelial cells. To determine if kidney is a source of PCI, cDNA was produced from human kidney total RNA. Sequencing and restriction mapping showed identity between kidney and liver PCI cDNA sequences. Similar cDNAs were obtained from rhesus monkey kidney and liver RNAs. Conditioned medium from the rhesus monkey kidney cell line CCL7.1 was analyzed on immunoblots, showing a 57,000D protein band that comigrated with human plasma PCI. Immunohistochemical staining and in situ hybridization of human kidney tissue sections showed that kidney PCI antigen and RNA were confined to tubular cells. The findings are consistent with the idea that PCI is synthesized and localized in kidney tissue where it may provide protease inhibitory activity and suggest that complexes of PCI with urokinase found in human urine may be produced locally in the kidney. (J. Clin. Invest. 1994. 94:2117-2124.) Key words: protein $\mathbf{C}$ inhibitor - plasminogen activator inhibitor-3 $\cdot$ kidney $\cdot$ tubular cells $\cdot$ human
\end{abstract}

\section{Introduction}

Protein C inhibitor (PCI),${ }^{1}$ a member of the serpin superfamily, is found in human plasma, urine, and other body fluids (1-3). Plasma PCI was first described by Marlar and Griffin as an inhibitor of activated protein $\mathrm{C} \mathrm{(4)} \mathrm{and} \mathrm{later} \mathrm{purified} \mathrm{and} \mathrm{charac-}$ terized by several groups $(1,5-7)$. Urinary PCI, purified and characterized by Stump et al., was initially described as a new urokinase (UPA) inhibitor and therefore named plasminogen activator inhibitor-3 (PAI-3) (8). Functional and immunologic identity of urinary PAI-3 with PCI from plasma was later shown

Address correspondence to John H. Griffin, Ph.D., Department of Molecular and Experimental Medicine, The Scripps Research Institute, 10666 North Torrey Pines Road, La Jolla, CA 92037.

Received for publication 25 August 1993 and in revised form 13 July 1994.

1. Abbreviations used in this paper: HSPG, heparan sulfate proteoglycans; PAI-3, plasminogen activator inhibitor-3; PCI, protein C inhibitor; uPA, urokinase.

J. Clin. Invest.

(C) The American Society for Clinical Investigation, Inc. $0021-9738 / 94 / 11 / 2117 / 08 \quad \$ 2.00$

Volume 94, November 1994, 2117-2124
$(9,10)$. Inhibition of both activated protein $\mathrm{C}$ and $\mathrm{uPA}$ by PCI is stimulated by glycosaminoglycans $(9,11-13)$. Physiological significance of uPA inhibition by PCI in the urinary tract is suggested by the presence of uPA-PCI complexes in normal human urine (11). PCI is also an inhibitor of tissue or urinary kallikrein (14) as well as the structurally homologous enzyme, prostate-specific antigen $(3,15)$.

The question of whether at least some of the PCI in urinary uPA-PCI complexes originates in the kidney is raised by the observations that uPA is expressed by human kidney $(16,17)$, that inhibition of uPA by PCI is stimulated by glycosaminoglycans $(9,10)$, and that glycosaminoglycans that are capable of binding PCI are expressed on the surfaces of epithelial kidney cells grown in culture (2). The source of the PCI in urine has not been identified previously but has been assumed to originate from plasma. In this study we investigate the expression of PCI by kidney cells both in culture and in situ.

\section{Methods}

All reagents were of reagent grade or better. Molecular biology grade reagents were used when available. Polymerase chain reaction (PCR) was performed in a thermal cycler from Perkin-Elmer Cetus Corp. (Norwalk, CT).

cDNA cloning. cDNA for PCI from different sources of RNA was obtained in a three-step procedure that included reverse transcription of total RNA and two rounds of PCR using two sets of specific nested primers designed using the human liver PCI sequence (18). Total RNA from human kidney and liver and from rhesus monkey kidney and liver were obtained from Clontech Laboratories, Inc. (Palo Alto, CA). The RNAs were reverse transcribed with the cDNA Cycle Kit (Invitrogen, San Diego, CA) using oligo-dT as primer according to the manufacturer's directions. The single-stranded cDNA products were subjected to two rounds of PCR, each consisting of 30 cycles of $2 \mathrm{~min}$ at the respective annealing temperature, $3 \mathrm{~min}$ at $72^{\circ} \mathrm{C}, 1 \mathrm{~min}$ at $94^{\circ} \mathrm{C}$, followed by 2 cycles of $2 \mathrm{~min}$ at the annealing temperature, $10 \mathrm{~min}$ at $72^{\circ} \mathrm{C} .50-\mathrm{ml}$ reactions contained $0.5 \mu \mathrm{M}$ of each primer, $2.5 \mathrm{U}$ of Vent polymerase (New England Biolabs Inc., Beverly, MA) or Taq polymerase (PerkinElmer Cetus Corp.), and $200 \mu \mathrm{M}$ each dATP, dCTP, dGTP, and dTTP in the enzyme buffer provided by each enzyme manufacturer under a layer of mineral oil. In the first round, $1 \mu \mathrm{l}$ of the reverse-transcribed cDNA was amplified with primers PCI-9 (TTTGGATCCCTCATAGAACAAAGAACATCCACC, nucleotides 23-46 [18]) and PCI-8 (CTAGTCAACTAAACCTGTCG, nucleotides 1360-1379 [18]) using an annealing temperature of $55^{\circ} \mathrm{C}$. In the second round, $2 \mu \mathrm{l}$ of the primary PCR mixture was reamplified with primers PCI-1 (CACCGCCACCACCCCCGGGAGATGAAGAAG, nucleotides 104-133 [18]) and PCI-10 (TTTGGATCCGTAGATTTCAGGAGAAGCCCCACC, nucleotides $1268-1291$ [18]) using an annealing temperature of $70^{\circ} \mathrm{C}$.

Sequencing. PCI cDNAs were cloned into the vector pCR1000 (TA Cloning System; Invitrogen) according to the directions of the manufacturer. White colonies were selected and assayed for the presence of PCI 
cDNA or genomic DNA amplification product inserts by PCR using the reaction conditions for the second round of amplification described above. Plasmid DNA from positive clones was prepared from 5-ml overnight cultures using tip-20 columns and reagents (QIAGEN, Studio City, CA) and subjected to double-stranded sequencing either manually using Sequenase (United States Biochemical Corp., Cleveland, $\mathrm{OH}$ ) and ${ }^{35} \mathrm{~S}$-dATP or Taq polymerase and fluorescent terminators, on an automated sequencing machine (ABI model 370A; Applied Biosystems, Inc., Foster City, CA). Primers used for sequencing included universal M13 forward (TGTAAAACGACGGCCAGT) and M13 reverse (AACAGCTATGACCATG) primers and the specific PCI primers, PCI-1 (see above) and PCI-10 (see above).

Sty I and BclI restriction digestion. PCI cDNAs obtained from different RNA sources as described above were digested with endonucleases StyI or BclI in a total volume of $40 \mu \mathrm{l}$ containing $10 \mu \mathrm{l}$ of PCR product and $40 \mathrm{U}$ of the respective enzyme in reaction buffers provided by the manufacturer (New England Biolabs Inc.) for $3 \mathrm{~h}$ at $37^{\circ} \mathrm{C} .10$ $\mu \mathrm{l}$ of each reaction was run on a $1.8 \%$ agarose gel.

Immunoblotting of PCI. Before electrophoresis, samples were partially purified over heparin-Sepharose (Pharmacia LKB Biotechology Inc., Piscataway, NJ) (18). Briefly, $5 \mathrm{ml}$ of plasma or $20 \mathrm{ml}$ supernatant from cultured rhesus monkey CCL7.1 (American Type Culture Collection, Rockville, MD) or human embryonic kidney 293 cells (19) was loaded on a 1-ml heparin-Sepharose column equilibrated in $50 \mathrm{mM}$ Tris, $100 \mathrm{mM} \mathrm{NaCl}, \mathrm{pH} 7.5$ (TBS). Bound protein was eluted with $0.7 \mathrm{M}$ $\mathrm{NaCl}$ in TBS. The samples were desalted and concentrated using a 10-kD molecular mass cutoff membrane (Filtron Technology Corp., Northborough, MA), electrophoresed on an 8\% SDS-polyacrylamide gel, and electrophoretically transferred to a nitrocellulose membrane as described previously (20). The membrane was blocked with $1 \%$ casein in TBS for $1 \mathrm{~h}$ followed by incubation with $1 \mu \mathrm{g} / \mathrm{ml}$ of a specific rabbit polyclonal anti-PCI antibody (P4) (21) for $1 \mathrm{~h}$ at room temperature. The blot was washed and incubated with $1 \mu \mathrm{g} / \mathrm{ml}$ of biotinylated PCI for $1 \mathrm{~h}$. Bound biotin was detected after $30 \mathrm{~min}$ incubation with $1 \mu \mathrm{g} /$ $\mathrm{ml}$ of streptavidin conjugated to alkaline phosphatase and nitro blue tetrasodium chloride 5-bromo-chloro-3'-indolyl-phosphate ptoluidine salt substrate (Pierce, Rockford, IL).

To determine the specificity of the P4 anti-PCI antibody used in immunoblots and immunohistological procedures, $500 \mu \mathrm{g}$ of specific P4 or nonspecific IgG was coupled to $100 \mu$ l of wet Sepharose beads according to the instructions of the manufacturer (Pharmacia LKB Biotechnology Inc.). $30 \mu \mathrm{l}$ of Sepharose beads coupled to P4 anti-PCI antibody or nonimmune rabbit IgG was incubated overnight with 100 $\mu \mathrm{l}$ of partially purified PCI derived from human plasma, the rhesus monkey kidney cell line CCL7.1, or the human kidney cell line 293 as described above. After centrifugation of the beads, $40 \mu \mathrm{l}$ of each supernatant was loaded on an 8\% SDS-polyacrylamide gel and immunoblotted as described above. Alternatively, blots were developed using the monoclonal mouse antibody against human PCI, API-78 (22) $(1 \mu \mathrm{g} /$ $\mathrm{ml}$ for $1 \mathrm{~h}$ ), followed by incubation with biotinylated goat anti-mouse IgG. Biotinylated IgG were detected as described above.

Immunofluorescence microscopy. Renal tissue was obtained from regions of the kidney that were without evidence of tumor invasion from patients nephrectomized for renal carcinoma. Acetone-fixed cryostat sections of normal human kidneys were reacted with rabbit anti-PCI antibody P4 (21), or P4 preincubated with human plasma PCI, and then with tetramethyl-rhodamine-isomer $\mathbf{R}$-conjugated swine anti-rabbit IgG antibody (Dako Corp., Carpinteria, CA). Subsequently, the sections were reacted either with fluorescein isothiocyanate (FITC)-conjugated sheep anti-Tamm-Horsfall protein (Bioproducts for Science, Inc., Indianapolis, IN) or with FITC-conjugated rabbit anti-human Fx1A antibody diluted in 1:100 normal rabbit serum to mark the distal or proximal tubules, respectively. The anti-Fx1A antibody was prepared by immunizing rabbits with human Fx1A made as described for the rat (23). The sections were examined with a fluorescence microscope equipped with epillumination and interference filters to differentiate rhodamine from FITC.

Riboprobe preparation. A full-length human PCI cDNA, obtained as described elsewhere (Radthe, K.-P., J. S. Greengard, J. A. Fernández, B. Villoutreix, and J. H. Griffin, manuscript submitted for publication), was subcloned into the plasmid pSP73 (Promega Corp., Madison, WI) under the control of transcription promotors SP6 and T7. The plasmid was linearized and utilized as a template for in vitro transcription of radiolabeled antisense or sense riboprobes employing ${ }^{35}$ S-UTP $(>1,200$ $\mathrm{Ci} / \mathrm{mmol}$; Amersham Corp., Arlington Heights, IL) and SP6 or T7 RNA polymerase (Promega Corp.), using the reaction conditions recommended by the manufacturer. Templates were removed by digestion with RQ1 DNAse (Promega Corp.) for $15 \mathrm{~min}$ at $37^{\circ} \mathrm{C}$, and the riboprobes were purified by phenol extraction and ethanol precipitation.

In situ hybridization. Human kidney tissue was obtained after surgery from normal segments of kidneys of patients nephrectomized for renal carcinoma. In situ hybridizations were carried out as described (24). Before hybridization, the paraffin sections were sequentially treated with xylene ( $3 \times 5 \mathrm{~min})$, with $2 \times \mathrm{SSC} / 10 \mathrm{mM}, 2$-mercaptoethanol/ $1 \mathrm{mM}$ ethylenediaminetetraacetic acid (EDTA) $(1 \times 10 \mathrm{~min} ; 1 \times$ $\mathrm{SSC}=150 \mathrm{mM} \mathrm{NaCl} / 15 \mathrm{mM}$ sodium citrate, $\mathrm{pH} 7.0$ ), with paraformaldehyde $\left(1 \times 10 \mathrm{~min}, 4^{\circ} \mathrm{C}\right)$, and with proteinase $\mathrm{K}(1 \mu \mathrm{g} / \mathrm{ml}$ in $500 \mathrm{mM}$ $\mathrm{NaCl} / 10 \mathrm{mM}$ Tris-HCl, $\mathrm{pH} 8.0 ; 1 \times 10 \mathrm{~min}$ ). All incubations and washes were performed at $25^{\circ} \mathrm{C}$ unless specified otherwise. The slides were then prehybridized for $1-2 \mathrm{~h}$ in $100 \mu \mathrm{l}$ of prehybridization buffer ( $50 \%$ [wt/vol] formamide/ $0.3 \mathrm{M} \mathrm{NaCl} / 20 \mathrm{mM}$ Tris- $\mathrm{HCl}, \mathrm{pH} 8.0 / 5$ mM EDTA $/ 0.02 \%$ polyvinylpyrrolidone $/ 0.02 \%$ Ficoll $/ 0.02 \%$ bovine serum albumin $/ 10 \%$ [wt/vol] dextran sulfate $/ 10 \mathrm{mM}$ dithiothreitol) at $42^{\circ} \mathrm{C}$. An additional $20 \mu \mathrm{l}$ of prehybridization buffer containing $2.5 \mathrm{mg} /$ $\mathrm{ml}$ of transfer RNA and $\sim 600,000 \mathrm{cpm}$ of the ${ }^{35} \mathrm{~S}$-labeled riboprobe were then added, and the slides were hybridized for $16-18 \mathrm{~h}$ at $55^{\circ} \mathrm{C}$. After hybridization, the slides were washed with $2 \times \mathrm{SSC} / 10 \mathrm{mM} 2$ mercaptoethanol/1 mM EDTA $(2 \times 10 \mathrm{~min})$, treated with RNAse A $(20 \mu \mathrm{g} / \mathrm{ml}$ in $500 \mathrm{mM} \mathrm{NaCl} / 10 \mathrm{mM}$ Tris- $\mathrm{HCl} ; 1 \times 30 \mathrm{~min})$, washed in $2 \times \mathrm{SSC} / 10 \mathrm{mM}$ 2-mercaptoethanol/1 mM EDTA $(2 \times 10 \mathrm{~min})$, and then washed for $2 \mathrm{~h}$ in $0.1 \times \mathrm{SSC} / 10 \mathrm{mM}$ 2-mercaptoethanol/1 mM EDTA at $60^{\circ} \mathrm{C}$. Finally, the slides were washed in $0.5 \times$ SSC ( 2 $\times 10 \mathrm{~min}$ ), dehydrated by immersion in a graded alcohol series containing $0.3 \mathrm{M} \mathrm{NH}_{4} \mathrm{Ac}$, dried, coated with NTB2 emulsion (Eastman Kodak Co., Rochester, NY; 1:2 in water), and exposed in the dark at $4^{\circ} \mathrm{C}$ for 2-6 wk. Slides were developed for $2 \mathrm{~min}$ in D19 developer (Eastman Kodak Co.), fixed, washed in water $(3 \times 5 \mathrm{~min})$, and counterstained with hematoxylin and eosin. Parallel sections were analyzed using a sense probe as control for nonspecific hybridization. No nonspecific hybridization signal was detected in these control hybridizations, even after $6 \mathrm{wk}$ of exposure (data not shown).

\section{Results}

The published sequence of human liver PCI cDNA (18) predicts an amplification product of $1,221 \mathrm{bp}$ using primers PCI-1 and PCI-10. Fig. 1 shows that the amplification product from human kidney RNA comigrates on an agarose gel with that obtained from human liver RNA. No information was available as to possible pathological conditions, drug administration, or cause of death of the human donors from whom the commercially obtained RNAs were prepared. Therefore, liver and kidney RNAs from healthy rhesus monkeys were also examined to control for such potential complications. Identical amplification products from RNA from rhesus monkey kidney and liver were obtained, using the same primers as for human PCI, indicating that a similar message for PCI is present in rhesus monkey liver and kidney. Human kidney PCI cDNA was further characterized by restriction digestion analysis. Human kidney- and liver-derived PCI cDNAs were digested with restriction endonucleases BclI or StyI. Fig. 2, $A$ and $B$, shows the agarose gels of the BclI and the StyI digests, respectively. The digests of both kidney PCI cDNA and liver PCI cDNA showed the expected 


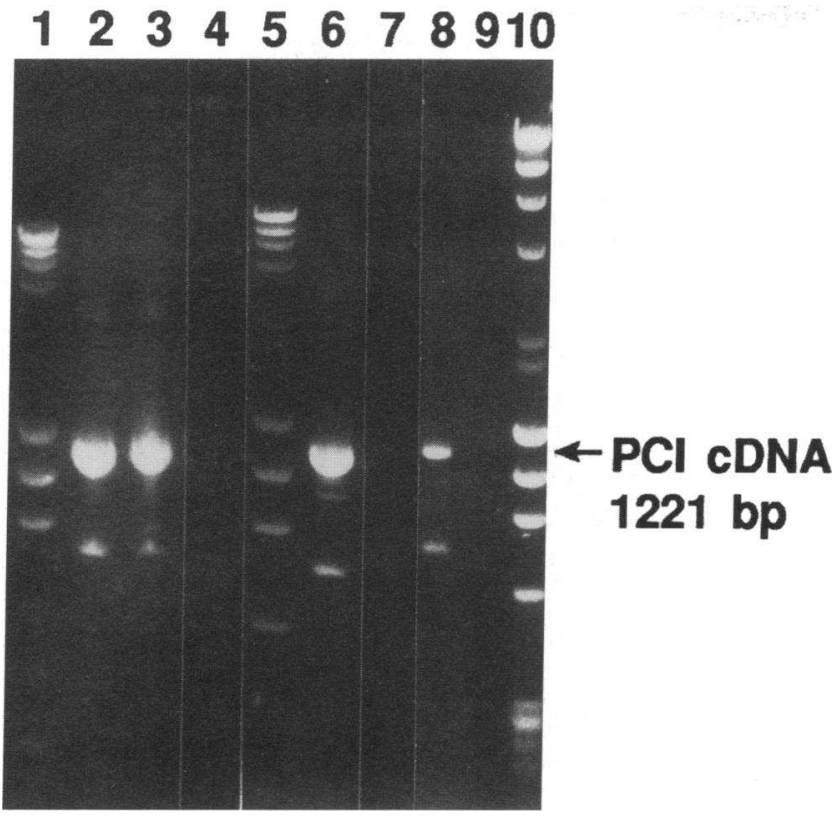

Figure 1. Agarose gel of PCI cDNAs obtained from reverse transcription of kidney and liver RNA. Amplification of reverse-transcribed RNA gave cDNA yields undetectable by ethidium bromide staining. After a second round of amplification with nested primers, a 1,221-bp band was observed from human kidney RNA (lane 2), human liver RNA control (lane 3), rhesus monkey kidney RNA (lane 6), and a control reaction with cloned human PCI cDNA (lane 8). Controls in lanes 4, 7, and 9 are template-free reactions. Lanes 1,5 , and 10 contain molecular weight markers (Lambda HindIII digest and PhiX174 HaeII digest).

bands as predicted from the published DNA sequence (18). However, an additional 828-bp band was observed in the cDNA obtained from kidney. Occurrence of this band is consistent with the absence of a StyI restriction site due to a mutation at
A

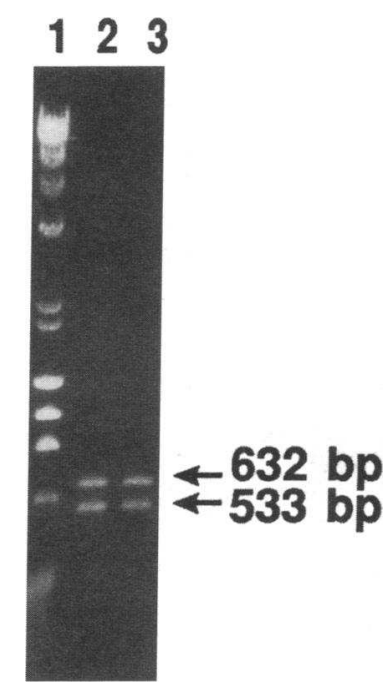

B

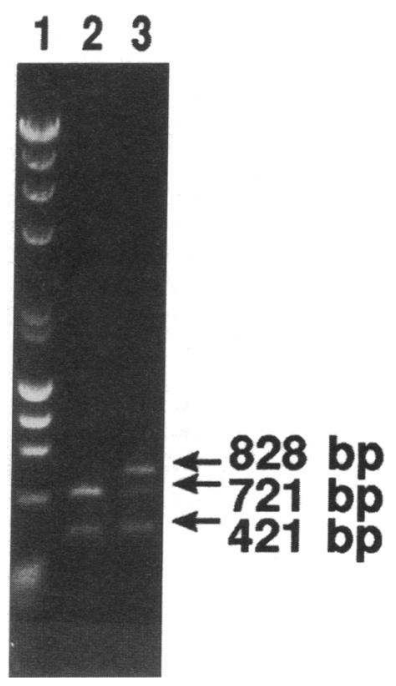

Figure 2. Agarose gel of restriction digests of PCI cDNA from human kidney and liver. PCI cDNA from human kidney (lane 3) and liver (lane 2) was subjected to digestion with endonucleases $\operatorname{BclI}(A)$ and StyI $(B)$. Lane 1 , molecular weight markers. base pair 210 , a common polymorphism recently found by our group and designated Spi-3.1 allele (Radtke, K.-P., J. S. Greengard, J. A. Fernández, B. Villoutreix, and J. H. Griffin, manuscript submitted for publication). The presence of the predicted bands for both the Spi-3.0 allele and the Spi-3.1 allele in the kidney-derived PCI cDNA suggests donor heterozygosity.

PCI cDNA obtained from human kidney was cloned and sequenced. The sequences were identical to liver-derived PCI cDNAs (data not shown). Similarly, $5^{\prime}$ and $3^{\prime}$ sequences obtained from rhesus monkey kidney cDNA were identical to those from rhesus monkey liver PCI cDNA clones. ${ }^{2}$

In situ hybridization experiments using an antisense $\mathrm{PCI}$ RNA probe labeled with ${ }^{35} \mathrm{~S}$ showed that PCI RNA is present in human kidney tissue in significant concentrations (Fig. $3 \mathrm{~A}$ ). After an exposure time of 2 wk a strong signal for PCI RNA was found in the epithelium of tubular cells. Glomerulus, blood vessels, capsule fat, and medulla were negative. Kidney tissue sections stained with a sense RNA probe of PCI showed no positive signal (Fig. $3 B$ ). The morphology of the kidney tissue used for in situ hybridization appeared to be normal.

To determine whether the PCI RNA produced in human or rhesus monkey kidney cells is translated, a human kidney cell line ( 293 cells) and a rhesus monkey kidney cell line (CCL7.1 cells) and tissue sections of human kidneys were examined for the presence of PCI antigen.

Fig. 4 shows an immunoblot of conditioned medium from human 293 cells, conditioned medium from rhesus monkey kidney CCL7.1 cells, and semipurified PCI. The samples shown in lanes 2-4 were preincubated with preimmune rabbit IgG, and samples in lanes 5-7 were treated with anti-PCI IgG before electrophoresis. The immunoblot, developed with monospecific polyclonal antibodies against human plasma PCI and purified biotinylated PCI, reveals a PCI protein band in the conditioned medium of cultured CCL7.1 cells (lane 3) which comigrates with human plasma PCI (lane 4). No PCI antigen was detected in 293 cell-conditioned medium (lane 2). Specificity of the reactions was confirmed by preincubation of the samples with anti-PCI antibodies before electrophoresis, which eliminated PCI-related protein bands (lanes 5 and 6 ). Human plasma PCI and CCL7.1-derived PCI bands shown in Fig. 4 could also be detected by monoclonal mouse anti-human PCI antibodies (data not shown).

Immunohistochemistry was used to assess the presence of PCI in kidney. Using immunofluorescence, the anti-PCI antibody was seen to bind to the cytoplasm of a portion $(\sim 25 \%)$ of tubular cross-sections in the cortex of normal kidney (Fig. 5 ). In addition, diffuse cytoplasmic reactions were seen with a few cells along Bowman's capsule. Very occasional glomerular and/or vessel lumen/lining staining was also found. In some tubular cross-sections, usually with lush epithelial cells, the staining was very bright and diffuse, with small punctate accentuations. In another population of tubular cross-sections, usually of smaller diameter, only the small punctate areas were noted and appeared to vary somewhat in size and between different tubular cross-sections. In some tubular cross-sections, only a portion of the tubular cells were reactive. No colocalization of the PCI stain and the Tamm-Horsfall protein stain was seen. The anti-Fx1A antibody stained the majority of the cortical

2. Radtke, K.-P., J. A. Fernández, B. Villoutreix, J. S. Greengard, and J. H. Griffin, manuscript submitted for publication. 

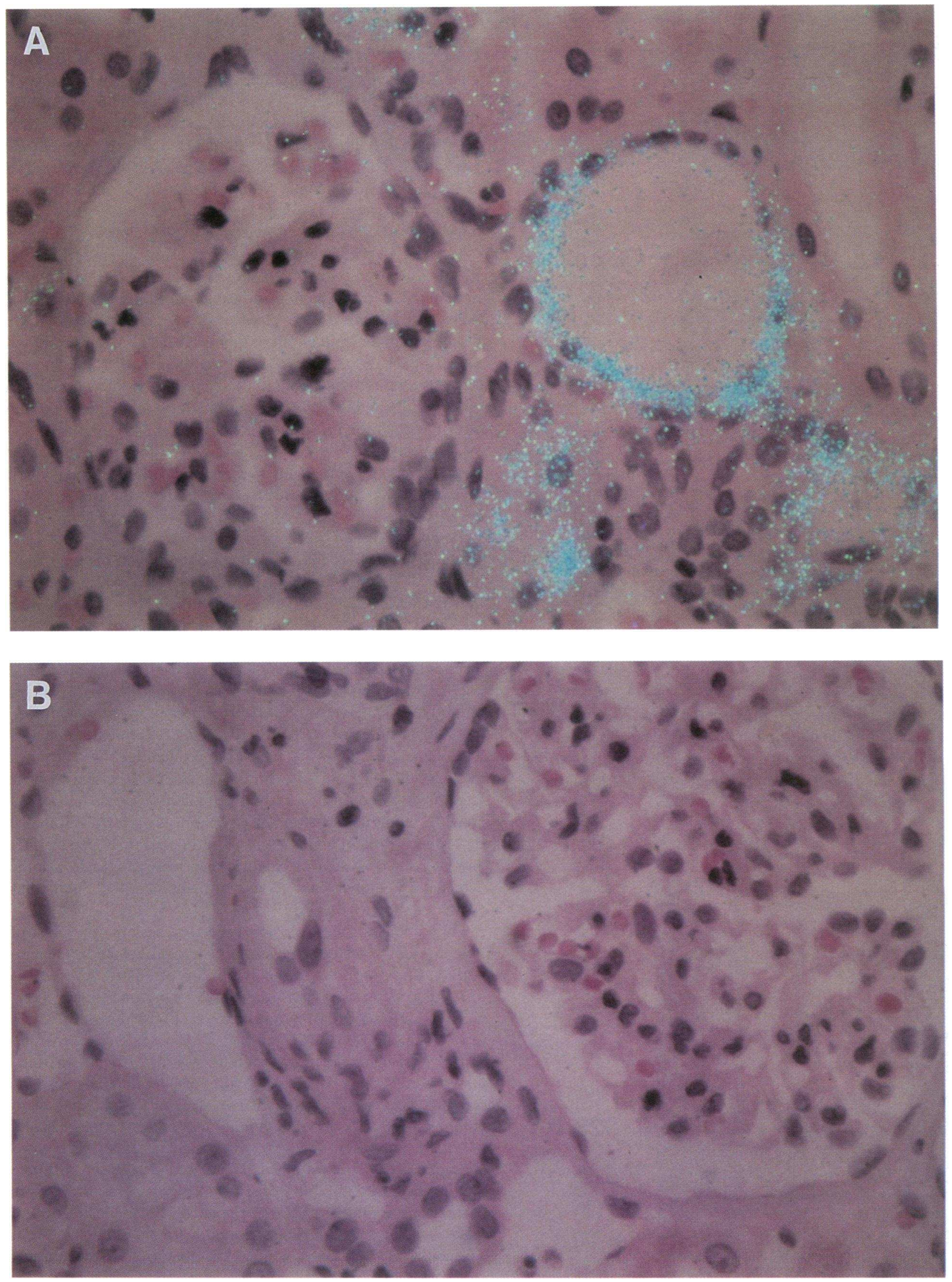

Figure 3. In situ hybridization of human kidney sections. Paraffin sections of normal human kidney tissue were incubated with PCI RNA probes labeled with ${ }^{35}$ S. Photographs were taken using a mercury vapor lamp. A positive signal is indicated by blue color. Test slides were developed with an antisense PCI probe $(A)$. A sense PCI RNA probe $(B)$ was used as a negative control. 


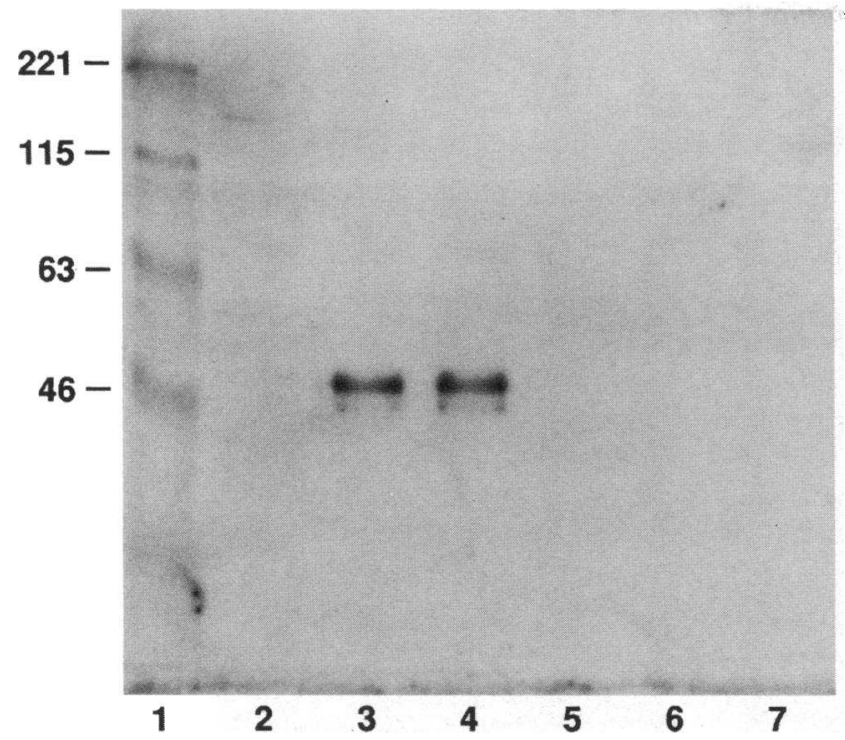

Figure 4. Immunoblot for PCI in conditioned media from human and rhesus monkey kidney cell lines. Conditioned media of the human kidney cell line 293 (lanes 2 and 5) and the rhesus monkey kidney cell line CCL7.1 (lanes 3 and 6 ) and partially purified human plasma PCI (lanes 4 and 7) were run on an $8 \%$ SDS polyacrylamide gel and transferred onto a nitrocellulose membrane. Samples were preincubated with nonimmune IgG (lanes 2-4) or anti-PCI IgG (lanes 5-7) before electrophoresis. Polyclonal antibodies against plasma PCI and biotinylated purified PCI were used to identify PCI-related protein bands. Molecular mass markers (lane 1) are shown in kilodaltons.

tubules. Almost all tubules staining for PCI also stained for Fx1A. Occasional tubules with only punctate PCI deposits failed to stain with the anti-Fx1A reagent. Anti-PCI antibodies preincubated with purified human PCI and antibodies against Fx1A preincubated with Fx1A did not stain the kidney tissue (data not shown).

\section{Discussion}

Human PCI, also known as PAI-3 $(9,10)$, is a heparin-dependent serine protease inhibitor (serpin) with a wide specificity for its target proteases $(1,12)$. PCI is found in significant concentrations in human plasma, urine, and seminal plasma (13 ). Its role in human plasma involves the regulation of serine proteases of the hemostatic and fibrinolytic systems; however, its roles in human urine and in seminal plasma remain unclear. In urine, PCI occurs not only as free inhibitor but also as a complex with the profibrinolytic protease, uPA. Since uPA and glycosaminoglycans are locally generated by kidney cells, it is possible that PCI is also expressed in the kidney, which thus could provide one source of the PCI found in urinary complexes. In this study, cDNAs for PCI from human and rhesus monkey kidney RNA were generated. Their restriction digests were identical to those of respective cDNAs obtained from liver RNA except for an additional 828-bp band observed in the StyI digest of the human kidney-derived PCI cDNA apparently arising from a previously published polymorphism. ${ }^{2}$

There are many examples of proteins that are expressed in alternative forms in various tissues. Although the identical sizes shown in Fig. 1 for liver and kidney PCI cDNAs suggest no gross differences exist between them, it is possible that subtle differences arise by means of alternative splicing. This is unlikely to occur in the central portions of PCI RNA, since the gene for human PCI has been sequenced (25), and no potential alternative exons were observed. However, it is possible that the cloning of the gene overlooked flanking sequences containing alternate exons that substitute sequences at the $5^{\prime}$ or $3^{\prime}$ ends of the RNA. To eliminate this possibility, PCI cDNA obtained from human kidney was cloned, and $480 \mathrm{bp}$ of sequence were generated from both the $5^{\prime}$ and the $3^{\prime}$ ends. The sequences were identical to liver-derived PCI cDNAs in each of these regions. Similarly, $5^{\prime}$ and $3^{\prime}$ sequences obtained from rhesus monkey kidney PCI cDNA were identical to those from rhesus monkey PCI cDNA clones from liver. ${ }^{2}$ These DNA sequence results indicate that the PCI RNA sequences are identical in liver and kidney from both human and rhesus monkey. To determine if physiologically significant amounts of PCI RNA are present in human kidney, paraffin sections of normal human kidney tissue were analyzed by in situ hybridization. Using a radiolabeled RNA probe containing the sequence for human plasma PCI, a high level of PCI RNA was observed in tubular cells, thus indicating transcription of the PCI gene in human kidney. The fact that not all tubular cells contained the PCI message suggests either that production of PCI RNA is spatially controlled or that it is expressed in a nonconstitutive manner in response to unidentified stimuli.

Since cDNA studies and in situ hybridization experiments showed the presence of PCI message in kidney tissue, immunological studies were performed to determine if PCI antigen is present in kidney in vivo. Previously, we showed that human and rhesus monkey PCI are closely related, displaying a 96\% identity on the predicted amino acid sequence level, and that antibodies raised against human PCI cross-reacted with rhesus monkey PCI. ${ }^{2}$ Conditioned media from cultured kidney cell lines from each species were immunoblotted for PCI. The human embryonic kidney cell line 293 did not stain positive for PCI, either in cell lysates or in conditioned medium. However, in conditioned medium obtained from rhesus monkey kidney epithelial cells CCL7.1, a 57,000-D protein band comigrating with purified human plasma PCI was immunodetected, providing evidence that PCI can be produced by kidney cells. In 293 cells, the absence of PCI antigen may be due to the embryonic origin of the progenitor cells or to dedifferentiation of the transformed phenotype (19). De novo induction of PCI during immortalization of CCL7.1 cannot be excluded, but the general epithelioid character of the CCL7.1 cells suggests they retain many kidney-specific functions. Further evidence for the presence of PCI antigen in human kidney was provided by immunofluorescence studies. Frozen sections of normal human kidney tissue were stained using antibodies against human plasma PCI. PCI antigen was localized to the cytoplasm of a portion of tubular cross-sections (Fig. 5), and a few diffuse cytoplasmic reactions were seen along Bowman's capsule. Occasional staining in the glomerular and/or vessel lumen/lining may represent cell cytoplasm deposits. No colocalization of the PCI stain and the Tamm-Horsfall protein stain was seen, indicating that PCI is not present in the ascending limb of the loop of Henle or the distal convoluted tubule. Almost all tubules staining for PCI also stained for Fx1A, suggesting that the PCI was predominantly in a region of the proximal tubules. Occasional tubules with only punctate PCI deposits failed to stain with the anti-Fx $1 \mathrm{~A}$ reagent. The findings suggest that only a region of the proximal tubule 

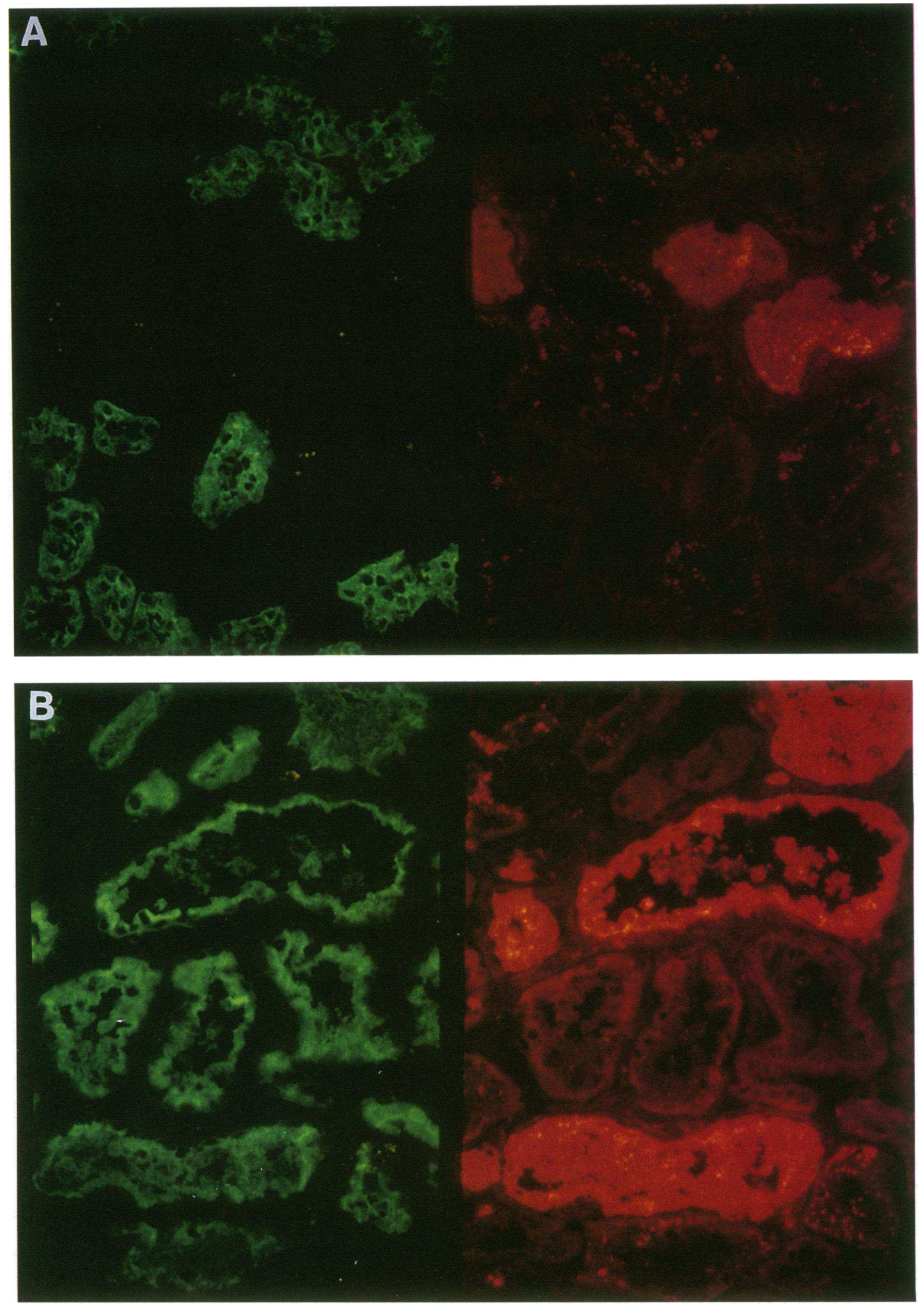

Figure 5. Immunofluorescent staining of human kidney sections for PCI, Tamm-Horsfall protein, and Fx1A. Frozen sections of normal human kidney tissue were incubated with rabbit anti-human PCI antibodies and tetramethyl-rhodamine-isomer-R-conjugated swine anti-rabbit IgG ( $A$ and $B$, red color). Subsequently, the sections were reacted either with FITC-conjugated anti-Tamm-Horsfall protein IgG $(A)$ (green color) or FITC-conjugated anti-Fx1A antibodies $(B)$ (green color). 
stains for PCI, and the finding of some diffuse cytoplasmic staining along Bowman's capsule might indicate that the proximal tubular regions containing diffuse cytoplasmic PCI were close to the glomerulus. The difference in pattern between the diffuse and punctate staining patterns might relate to production versus reabsorption of the PCI since the larger punctate deposits in some tubules had characteristics sometimes associated with protein reabsorption droplets. However, the finding that PCI antigen and PCI RNA colocalize in tubular kidney cells together with the observation of PCI antigen production by the cultured rhesus monkey kidney cell line and the presence of PCI transcripts in whole kidney total RNA from both species provide evidence for local production of the PCI antigen stained in the tissue slices.

Tubular cells form part of the filtration and reabsorption system of the kidney and are exposed to significant concentrations of uPA present in human urine, which can reach $200 \mu \mathrm{g} /$ liter (8). Glycosaminoglycans such as the heparan sulfate side chains on some proteoglycans are an integral component of the glomerular and tubular basement membranes. However, the distribution of heparan sulfate proteoglycans (HSPG) appears to vary among renal basement membranes. The intensity of immunolabeling for HSPG in tubular membranes of the distal tubule is approximately twice that of the glomerular membrane, and that of the proximal tubule is halfway between the two (26). The localization of PCI within the proximal tubule is significant since glycosaminoglycans stimulate the inhibition of target proteases by PCI (2), and high concentrations of glycosaminoglycans are present within glomerular and tubular basement membranes (26). Thus, it may be speculated that PCIuPA complex formation may be enhanced in pathologic conditions that result in disruption of the basement membranes with release of HSPG. Indeed, glomerular basement membrane fragments have been identified in the urine of rabbits with antiglomerular membrane antibodies associated with glomerulonephritis (27), and loss of HSPG from the glomerular basement membrane has been observed in rats with aminonucleoside nephrosis (28). The net effect of increased PCI efficiency may be limitation of protease-dependent tissue degradation mediated by the metalloproteinases whose activation depends upon plasmin generated by uPA (29).

Although uPA is produced in the kidney in appreciable concentrations $(16,17,30)$, its physiological role in the renal tract is currently not well characterized. However, it may be speculated that plasmin generation is a key function of this uPA, thereby preventing protein precipitation and clot formation in the renal tubules. uPA plays an important role in the clinical progression of various types of cancers $(31,32)$. The presence of the uPA inhibitor, PCI, in an environment that is exposed to uPA suggests that PCI may play a protective role in normal kidney tissue, blocking the profibrinolytic and mitogenic activity of uPA (33), while directing uPA activity towards the lumen of the filtration system where proteolysis is required to maintain an unrestricted flow of liquids. The current results have significance for understanding the physiology of the human urinary tract and support the idea that UPA-PCI complexes found in human urine are locally produced in the kidney. The data imply that ongoing control of fibrinolytic activity is a natural requirement of the kidney milieu. Any pathological process that alters the fibrinolytic balance could potentially have deleterious effects on the kidney function, as it is known that plasma levels of the zymogen of another target protease of $\mathrm{PCI}$, protein $\mathrm{C}$, are significantly decreased in patients with chronic renal insufficiency and uremia $(34,35)$. In view of data showing that uPA has a direct mitogenic effect on primary cultures of renal cells (33), the role of its regulator, PCI, needs to be evaluated in the progression of renal cancer.

This study opens a new area of investigation into the pathophysiology of various kidney conditions.

\section{Acknowledgments}

Automated fluorescent terminator sequencing was performed and synthetic oligonucleotides were prepared by Dr. Charles Glass (The Scripps Research Institute, La Jolla, CA). The authors express appreciation to Dr. Ruben F. Gittes and the nursing staff of the operating room of Scripps Clinic for assistance in obtaining human tissue samples. We thank Terri Thinnes for excellent technical assistance.

This study was supported in part by National Institutes of Health grants HI-31950 and DK-20043, and by a grant from the Stein Endowment Fund (La Jolla, CA), and a fellowship from the American Heart Association (California Affiliate) to Klaus-Peter Radtke. Winson W. Tang was the recipient of a fellowship from the National Kidney Foundation of Southern California.

This is manuscript \#8208-MEM from The Scripps Research Institute.

\section{References}

1. Suzuki, K., J. Nishioka, and S. Hashimoto. 1983. Protein C inhibitor: purification from human plasma and characterization. J. Biol. Chem. 258:163168.

2. Geiger, M., U. Priglinger, J. H. Griffin, and B. R. Binder. 1991. Urinary protein C inhibitor. J. Biol. Chem. 266:11851-11857.

3. Laurell, M., A. Christensson, P.-A. Abrahamsson, J. Stenflo, and H. Lilja. 1992. Protein C inhibitor in human body fluids. Seminal plasma is rich in inhibitor antigen deriving from cells throughout the male reproductive system. J. Clin. Invest. 89:1094-1101.

4. Marlar, R. A., and J. H. Griffin. 1980. Deficiency of protein C inhibitor in combined Factor V/VIII deficiency disease. J. Clin. Invest. 66:1186-1189.

5. Radtke, K.-P., T. W. Stief, and N. Heimburger. 1988. A new and simple isolation procedure for human protein $\mathrm{C}$ inhibitor. Biol. Chem. Hoppe-Seyler. 369:965-974.

6. Laurell, M., T. H. Carlson, and J. A. Stenflo. 1988. Monoclonal antibodies against the heparin-dependent protein $\mathrm{C}$ inhibitor suitable for inhibitor purification and assay of inhibitor complexes. Thromb. Haemostasis. 60:334-339.

7. Pratt, C. W., B. G. Macik, and F. C. Church. 1989. Protein C inhibitor: purification and proteinase reactivity. Thromb. Res. 53:596-602.

8. Stump, D. C., M. Thienpont, and D. Collen. 1986. Purification and characterization of a novel inhibitor of urokinase from human urine. Quantitation and preliminary characterization in plasma. J. Biol. Chem. 261:12759-12766.

9. Stief, T. W., K.-P. Radtke, and N. Heimburger. 1987. Inhibition of urokinase by protein $\mathrm{C}$ inhibitor (PCI): evidence for identity of PCI and plasminogen activator inhibitor 3 (PAI 3). Biol. Chem. Hoppe-Seyler. 368:1427-1433.

10. Heeb, M. J., F. España, M. Geiger, D. Collen, D. C. Stump, and J. H. Griffin. 1987. Immunological identity of heparin-dependent plasma and urinary protein $\mathrm{C}$ inhibitor and plasminogen activator inhibitor-3. J. Biol. Chem. 262:15813-15816.

11. Geiger, M., K. Huber, J. Wojta, L. Stingl, F. España, J. H. Griffin, and B. R. Binder. 1989. Complex formation between urokinase and plasma protein C inhibitor in vitro and in vivo. Blood. 74:722-728.

12. España, F., M. Berrettini, and J. H. Griffin. 1989. Purification and characterization of plasma protein C inhibitor. Thromb. Res. 55:369-384.

13. Geiger, M., M. J. Heeb, B. R. Binder, and J. H. Griffin. 1988. Competition of activated protein $\mathrm{C}$ and urokinase for a heparin-dependent inhibitor. FASEB (Fed. Am. Soc. Exp. Biol.) J. 2:2263-2267.

14. Ecke, S., M. Geiger, I. Resch, I. Jerabek, L. Stingl, M. Maler, and B. R. Binder. 1992. Inhibition of tissue kallikrein by protein C inhibitor. Evidence for identity of protein $\mathrm{C}$ inhibitor with the kallikrein binding protein. J. Biol. Chem. 267:7048-7052.

15. España, F., J. Gilabert, A. Estellés, A. Romeo, J. Aznar, and A. Cabo. 1991. Functionally active protein $C$ inhibitor/plasminogen activator inhibitor-3 (PCI/PAI-3) is secreted in seminal vesicles, occurs at high concentrations in human seminal plasma and complexes with prostate-specific antigen. Thromb. Res. 64:309-320. 
16. Iwamoto, T., Y. Nakashima, and K. Sueishi. 1990. Secretion of plasminogen activator and its inhibitor by glomerular epithelial cells. Kidney Int. 37:14661476.

17. Rondeau, E., S. Ochi, R. Lacave, C. J. He, R. Medcalf, F. Delarue, and J. D. Sraer. 1989. Urokinase synthesis and binding by glomerular epithelial cells in culture. Kidney Int. 36:593-600.

18. Suzuki, K., Y. Deyashiki, J. Nishioka, K. Kurachi, M. Akiras, S. Yamamoto, and S. Hashimoto. 1987. Characterization of cDNA for human protein C inhibitor: a new member of the plasma serine protease inhibitor superfamily. $J$. Biol. Chem. 262:611-616.

19. Graham, F. L., J. Smiley, W. C. Russell, and R. Nairn. 1977. Characteristics of a human cell line transformed by DNA from human adenovirus type 5 . $J$. Gen. Virol. 36:59-72.

20. Heeb, M. J., H. P. Schwarz, T. White, B. Lämmle, M. Berrettini, and J. H. Griffin. 1988. Immunoblotting studies of the molecular forms of protein C in plasma. Thromb. Res. 52:33-43.

21. España, F., V. Vicente, D. Tabernero, I. Scharrer, and J. H. Griffin. 1990. Determination of plasma protein $\mathrm{C}$ inhibitor and of two activated protein $\mathrm{C}$ inhibitor complexes in normals and in patients with intravascular coagulation and thrombotic disease. Thromb. Res. 59:593-608.

22. Meijers, J. C. M., D. H. A. J. Kanters, R. A. A. Vlooswijk, H. E. Vlooswijk, H. E. van Erp, M. Hessing, and B. N. Bouma. 1988. Inactivation of human plasma kallikrein and factor XIa by protein C inhibitor. Biochemistry. 27:4231-4237.

23. Edgington, T. S., R. J. Glassock, and F. J. Dixon. 1968. Autologous immune complex nephritis induced with renal tubular antigen. I. Identification and isolation of the pathogenic antigen. J. Exp. Med. 127:555.

24. Keeton, M., Y. Eguchi, M. Sawdey, C. Ahn, and D. J. Loskutoff. 1993 Cellular localization of type 1 plasminogen activator inhibitor messenger RNA and protein in murine renal tissue. Am. J. Pathol. 142:59-70.

25. Meijers, J. C. M., and D. W. Chung. 1991. Organization of the gene coding for human protein $\mathrm{C}$ inhibitor (plasminogen activator inhibitor-3). J. Biol. Chem. 266:1-7.

26. Desjardins, M., and M. Bendayan. 1989. Heterogenous distribution of type IV collagen, entactin, heparan sulfate proteoglycan, and laminin among renal basement membranes as demonstrated by quantitative immunocytochemistry. $J$. Histochem. Cytochem. 37:885-897.

27. Hawkins, D., and C. G. Cochrane. 1968. Glomerular basement membrane damage in immunological glomerulonephritis. Immunology. 14:665-681.

28. Mynderse, L. A., J. R. Hassell, H. K. Kleinman, G. R. Martin, and A. Martinez-Hernandez. 1983. Loss of heparan sulfate proteoglycan from glomerular basement membrane of nephrotic rats. Lab. Invest. 48:292-302.

29. Matrisian, L. 1992. The matrix degrading metalloproteinases. BioEssays. 14:455-463.

30. Larsson, L.-I., L. Skriver, L. S. Nielsen, J. Grondahl-Hansen, P. Kristensen, and K. Dano. 1984. Distribution of urokinase-type plasminogen activator immunoreactivity in the mouse. J. Cell Biol. 98:894-903.

31. Schmitt, M., F. Janicke, N. Moniwa, N. Chucholowski, L. Pache, and H. Graeff. 1992. Tumor-associated urokinase-type plasminogen activator: biological and clinical significance. Biol. Chem. Hoppe-Seyler. 373:611-622.

32. Duffy, M. J. 1990. Plasminogen activators and cancer. Blood Coagul. \& Fibrinolysis. 1:681-687.

33. Kirchheimer, J. C., J. Wojta, G. Christ, G. Hienert, and B. R. Binder. 1988. Mitogenic effect of urokinase on malignant and unaffected adjacent human renal cells. Carcinogenesis. 9:2121-2123.

34. Faioni, E. M., F. Franchi, A. Krachmalnicoff, C. Valsecchi, G. L. Vigano, G. Remuzzi, and P. M. Mannucci. 1991. Low levels of the anticoagulant activity of protein $\mathrm{C}$ in patients with chronic renal insufficiency: an inhibitor of protein $C$ is present in uremic plasma. Thromb. Haemostasis. 4:420-425.

35. Sorensen, P. J., F. Knudsen, A. H. Nielsen, and J. Dyerberg. 1989. Protein C assays in uremia. Thromb. Res. 54:301-310. 